\title{
Rapid and quantitative detection of the microbial spoilage of beef by Fourier transform infrared spectroscopy and machine learning
}

\author{
David I. Ellis ${ }^{\mathrm{a}, \mathrm{b}}$, David Broadhurst ${ }^{\mathrm{b}}$, Royston Goodacre ${ }^{\mathrm{a}, *}$ \\ ${ }^{a}$ Department of Chemistry, UMIST, PO Box 88, Sackville Street, Manchester M60 1QD, UK \\ ${ }^{\mathrm{b}}$ Institute of Biological Sciences, University of Wales, Aberystwyth, Ceredigion SY23 3DD, UK
}

Received 7 November 2003; received in revised form 16 March 2004; accepted 23 March 2004

\begin{abstract}
Beef is a commercially important and widely consumed muscle food and central to the protein intake of many societies. In the food industry no technology exists for the rapid and accurate detection of microbiologically spoiled or contaminated beef. Fourier transform infrared (FT-IR) spectroscopy is a rapid, reagentless and non-destructive analytical technique whose continued development is resulting in manifold applications across a wide range of biosciences. FT-IR was exploited to measure biochemical changes within the fresh beef substrate, enhancing and accelerating the detection of microbial spoilage. Separately packaged fresh beef rump steaks were purchased from a national retailer, comminuted for $15 \mathrm{~s}$ and left to spoil at ambient room temperature for $24 \mathrm{~h}$. Every hour, FT-IR measurements were collected directly from the sample surface using attenuated total reflectance, in parallel the total viable counts of bacteria were obtained by classical microbiological plating methods. Quantitative interpretation of FT-IR spectra was undertaken using partial least squares regression and allowed for accurate estimates of bacterial loads to be calculated directly from the meat surface in $60 \mathrm{~s}$. Machine learning methods in the form of genetic algorithms and genetic programming were used to elucidate the wavenumbers of interest related to the spoilage process. The results obtained demonstrated that using FT-IR and machine learning it was possible to detect bacterial spoilage rapidly in beef and that the most significant functional groups selected could be directly correlated to the spoilage process which arose from proteolysis, resulting in changes in the levels of amides and amines. (C) 2004 Elsevier B.V. All rights reserved.
\end{abstract}

Keywords: Muscle foods; FT-IR spectroscopy; Food spoilage; Chemometrics; Evolutionary computation

\section{Introduction}

Beef is a commercially important and widely consumed muscle food. Some changes in patterns of consumption of beef may have occurred in recent years due to events such as the UK centred BSE outbreak [1-3] and more recent concerns regarding possible links to colorectal cancer [4-6]. However, beef still is, and will remain, part of the staple diet and central to the protein intake of many societies [7]. Within the food industry at present, no technology exists for a rapid (minutes as opposed to hours) and accurate detection system for microbiologically spoiled or contaminated meat or poultry [8]. Current methods proposed to detect bacterial spoilage in meats number in excess of 40 and have been described in-depth elsewhere [8-11], as have the pro-

\footnotetext{
* Corresponding author. Tel.: +44-161-200-4480; fax: +44-161-200-4519.

E-mail address: r.goodacre@umist.ac.uk (R. Goodacre).
}

cesses leading to the microbial spoilage of muscle foods $[8,12-15]$. Whilst some of the more recently proposed technologies have seen some improvement in terms of rapidity [16-18], the methods in use in the food industry at present are time-consuming, labour-intensive and give retrospective information [19].

Fourier transform infrared (FT-IR) spectroscopy is a rapid, reagentless, non-destructive analytical technique whose continuing development is resulting in manifold applications across a wide range of biosciences, be they molecular or organismal [20]. FT-IR involves the observation of molecules that are excited by an infrared beam, were an infrared absorbance spectrum represents a "fingerprint" characteristic of any (bio)chemical substance $[21,22]$. This technique has been shown to be a useful tool for the characterisation of bacteria [23-25], fungi [26-28], metabolic footprinting [29] and fingerprinting [20], as well as a number of food-based analyses [30-32]. 
Several spectroscopic analyses have been undertaken on beef and these have included analysis of quality attributes such as physical and chemical characteristics, including determination of fat, protein, moisture and connective tissue content, as well as prediction of toughness [33,34]. Whilst a number of the studies have used near-infrared (NIR) spectroscopy to study beef, other recent studies have applied FT-IR spectroscopy in the mid-infrared (MIR). These have included investigations into authenticity and adulteration $[32,35]$, and a very recent study into the detection of central nervous system tissue in beef [36]. However, there are no studies to date using infrared spectroscopy to detect bacterial spoilage in, or on, beef.

The aim of this study was to build upon previous experiments undertaken in our laboratory on poultry [19] where we were able to quantify accurately the bacterial contamination of chicken breast tissue from $2 \times 10^{6}$ to $2 \times 10^{9}$ total viable count (TVC) per square centimetre. In the present study, we investigate the microbial contamination of beef at lower spoilage levels between $5 \times 10^{4}$ and $4 \times 10^{7} \mathrm{TVC} \mathrm{cm}^{-2}$ using FT-IR spectroscopy and chemometrics.

\section{Materials and methods}

\subsection{Sample preparation}

Individually packaged beef rump steaks with an average weight of $270 \mathrm{~g}$ were purchased from a national retail outlet on the morning of each experiment. As with previous spoilage experiments [19], no pre-preparation of the meat, such as removal of fat or connective tissue, washing, or inoculation with bacteria was undertaken. To accelerate the spoilage process the meat was weighed aseptically into $30 \mathrm{~g}$ sub-samples and comminuted for $15 \mathrm{~s}$ in a Moulinex type 505, $180 \mathrm{~W}$ coffee mill (Moulinex UK Ltd., Birmingham, UK). The bowl of the coffee mill was washed and dried with a paper towel between each sample. Following comminution the samples were removed from the coffee mill and placed into the upturned lid of a $90 \mathrm{~mm}$ Petri dish and pressed manually to a thickness of $\sim 5 \mathrm{~mm}$ using the inverted base of a Petri dish as the press. A sterile upturned Petri dish base was used to cover each prepared sample and once 25 samples had been obtained, they were then randomised, numbered and stored on the bench top at ambient room temperature.

\subsection{HATR FT-IR spectroscopy}

FT-IR analysis was undertaken using a ZnSe HATR accessory (Spectroscopy Central Ltd., Green Lane, Warrington, UK) on a Bruker IFS28 infrared spectrometer (Bruker Optics Ltd., Banner Lane, Coventry, UK) equipped with a deuterated-triglycine-sulphate (DTGS) detector. The ZnSe HATR crystal was capable of 10 external reflections with the evanescent field [37] effecting a depth of $1.01 \mu \mathrm{m}$ (Spectroscopy Central Ltd.). At $1 \mathrm{~h}$ intervals six replicates were individually excised using a scalpel from a prepared Petri dish sample and placed in intimate contact with the $\mathrm{ZnSe}$ crystal and a spectrum collected. The sample replicates measured approximately $60 \mathrm{~mm} \times 10 \mathrm{~mm} \times 5 \mathrm{~mm}$ and were inverted to ensure that the aerobic upper surface of the sample was placed in intimate contact with the ZnSe crystal.

The surface of the ZnSe crystal was cleaned with distilled water and dried with lint-free tissue following collection of each spectrum and washed thoroughly with acetone, rinsed with distilled water and dried with lint-free tissue at the end of each sampling interval. The IBM-compatible PC used to control the IFS28 spectrometer was also programmed to collect spectra over the wavenumber range $4000-600 \mathrm{~cm}^{-1}$. Reference spectra were acquired by collecting a spectrum from the cleaned blank crystal prior to the presentation of each sample replicate. All spectra were collected in reflectance mode with a resolution of $16 \mathrm{~cm}^{-1}$, and to improve the signal-to-noise ratio 256 scans were co-added and averaged. Collection time for each sample spectrum was $60 \mathrm{~s}$ and a total of 450 spectra were collected over the series of three separate experiments. At each $1 \mathrm{~h}$ sampling interval a $1 \mathrm{~g}$ (which equates to approximately $1 \mathrm{~cm}^{2}$ ) sub-sample of comminuted beef was taken and vortexed for $60 \mathrm{~s}$ in $9 \mathrm{ml}$ of physiological saline and the $\mathrm{pH}$ recorded. A dilution series was undertaken and plates of Lab M blood agar base (IDG plc, Lancashire, UK) lawned in triplicate with $50 \mu \mathrm{l}$ of homogenate, incubated aerobically for $48 \mathrm{~h}$ at $25^{\circ} \mathrm{C}$ and the total viable counts recorded as colony forming units (CFUs).

\subsection{Supervised analysis}

ASCII data were exported from the Opus software used to control the FT-IR instrument and imported into Matlab Version 6.1 (The MathWorks, Inc., Natick, Mass) which runs under Microsoft Windows NT on an IBM-compatible PC. To minimise problems arising from unavoidable baseline shifts the spectra were scaled so that the smallest absorbance was set to 0 and the highest to +1 [27].

When the desired responses (targets) associated with each of the inputs (spectra) are known, then the system may be supervised. The goal of supervised learning is to find a model that correctly associates the inputs with the targets; this is usually achieved by minimising the error between the target and the model's response (output) [38-40]. For quantitative interpretation of the FT-IR spectra the multivariate linear regression method of PLS was applied and the pseudocode given in [38] followed by Jones et al. [41].

\subsection{Evolutionary computation}

\subsubsection{Genetic algorithms}

In this study genetic algorithms (GAs) $[42,43]$ were used to determine the optimal subset of variables to give the best root-mean-square error of prediction (RMSEP) in a multiple linear regression (MLR) model. All calculations were performed using in-house software written in $\mathrm{C}++$ running 
(A)

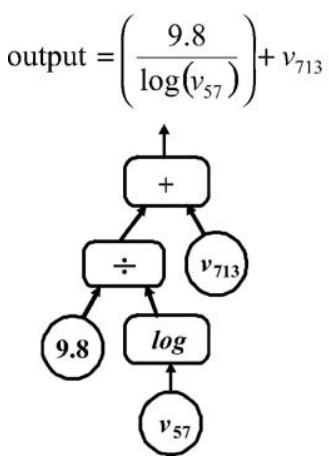

(B)

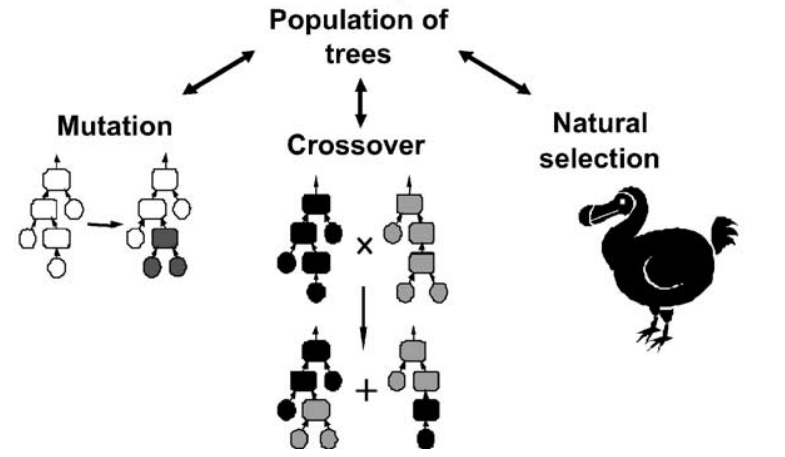

Fig. 1. (A) A typical GP parse tree. The leaves of the tree, or terminals, represent input variables or numerical constants (in this case FT-IR wavenumbers). In this 'orientation' these values are passed 'vertically' to nodes, which perform a numerical programme or operation before passing on the result toward the 'top' of the tree (e.g. total viable count). (B) Cartoon of the evolution approach showing the population of trees and how these undergo mutation and crossover. During the evolutionary process the most-fit individuals are allowed to survive to subsequent populations based on their fitness function which is a measure of the predictive power of a GP parse tree (e.g., TVC).

under Microsoft Windows NT on an IBM-compatible PC, and full details of GA-MLR are given in [44].

The GA used proportional selection, and two-point crossover recombination with mutation, operating on a population of binary-encoded chromosomes, each chromosome representing $v$ candidate wavelengths. The parameter $v$ can be set to any integer value, between 2 and the total number of wavelengths used, prior to the execution of any single GA run. In order to select the optimal value of $v$ a set of GA experiments are performed where $v$ is varied between 2 and $v_{\max }\left(v_{\max }\right.$ being the minimum number of wavenumbers allowed before overtraining in the regression model occurs). In this instance $8 \mathrm{GA}$ experiments were performed such that: $v=3,4,5,6,8,10,15$, and 20. Each experiment consisted of 100 randomly initialised independent GA runs.

The probability of mutating a given chromosome after recombination was set to 0.2 and the probability of changing a bit from a 0 to 1 (or vice versa) once a chromosome is selected for mutation was set to 0.01 . No two identical candidates were allowed in a given population and the top $10 \%$ of each generation are automatically transferred unmolested to the next generation.

\subsubsection{Genetic programming}

A GP is an extension of the GA approach to derive mathematical equations, logical rules or program functions automatically [45-50]. Rather than representing the solution to the problem as a string of parameters, as in a conventional GA, a GP usually (as here) uses a tree structure (Fig. 1). The leaves of the tree, or terminals, represent input variables or numerical constants. Their values are passed to nodes, at the junctions of branches in the tree, which perform some numerical or program operation before passing on the result further towards the root of the tree. Mutations are performed by selecting a parent and modifying the value or variable returned by a terminal, or changing the operation performed by a node. Crossovers are performed by selecting two parents and swapping sub-trees at randomly selected nodes within their trees. The new individuals so generated replace less-fit members of the population chosen probabilistically on the basis of their unfitness (Fig. 1).

The GP [45,51] employed the Genomic Computing software Gmax-bio $^{\mathrm{TM}}$ (Aber Genomic Computing, Aberystwyth, UK; http://www.abergc.com) which runs under Microsoft Windows NT on an IBM-compatible PC. The default parameter settings for population size (1000), mutation and recombination rates were used throughout. The operators that were used were $+,-, /, *, \log _{10}(x), 10^{x}$ and $\tanh (x)$. The fitness calculation used is $F=1 /(0.01+S / B)$ where the values of $S$ and $B$ are determined by the FITNESS setting. In this expression $S$ is a statistic derived from the model, which ranges between 0 and infinity and $B$ is a normalising quantity. The value of $B$ is chosen such that a perfect model yields $F=100$, and a model which performs no better than random chance yields $F=1$.

\section{Results and discussion}

\subsection{TVC, $p H$ and sensory characteristics}

Comminution of samples in order to accelerate the spoilage process and growth of bacteria was successful in that the final mean $\log _{10}$ (TVC) of 7.38 was approximately two orders above the initial mean $\log _{10}$ (TVC) of 5.45 (Table 1 and Fig. 2A). In previous experiments into the spoilage process in poultry [19], the indicator used for the detection of organoleptic spoilage was $10^{8} \mathrm{CFU} \mathrm{cm}^{-2}$. However, the results from previous experiments, and in particular those undertaken in Ellis et al. [19], demonstrated that spoilage could be accurately detected at $10^{7} \mathrm{CFU} \mathrm{cm}^{-2}$. Moreover, on further appraisal of the literature [10,52-54] it 
Table 1

Data matrix of the results from the three beef spoilage experiments

\begin{tabular}{lllllll}
\hline Experiment & Initial $\mathrm{pH}$ & Final $\mathrm{pH}$ & Initial TVC $\left(\log _{10}\right)$ & Final TVC $\left(\log _{10}\right)$ & Room temperature $\left({ }^{\circ} \mathrm{C}\right)$ & Spoilage $(\mathrm{h}){ }^{\mathrm{a}}$ \\
\hline 1 & 5.33 & 5.33 & 5.18 & 6.94 & 21.6 & 24.7 \\
2 & 5.50 & 5.53 & 5.34 & 7.58 & 20 & 20.9 \\
3 & 5.41 & 5.41 & 5.68 & 7.39 & 20 & 2.4 \\
Mean & 5.42 & 5.43 & 5.45 & 7.38 & 20 \\
\hline
\end{tabular}

a The onset of spoilage is taken as the point when total colony counts $10^{7} \mathrm{~cm}^{-2}$.

b Did not reach the point of spoilage of $10^{7} \mathrm{~cm}^{-2}$.

was apparent that bacterial spoilage was detectable at different levels according to the type of meat under investigation.

The levels at which bacterial spoilage takes place in meats are related to the muscle type and $\mathrm{pH}$. It is known for example that these levels can be as low as $10^{6} \mathrm{CFU} \mathrm{cm}{ }^{-2}$ in meats of high $\mathrm{pH}(>6)$ [53] and vary from $10^{7}$ to $10^{8} \mathrm{CFU} \mathrm{cm}^{-2}$ in the majority of meats according to muscle composition and levels of glycogen stores [53,54]. Beef is not considered a high $\mathrm{pH}$ meat but has lower glycogen stores and differences in muscle composition, such as denser capillarisation and higher levels of myoglobin and mitochondria [54]. Therefore for experiments on beef, the indicator level used for

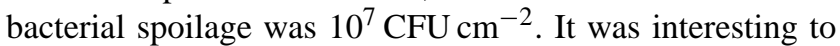
note that whilst two of the three experiments on beef attained final TVC levels above the predetermined spoilage indicator of $10^{7} \mathrm{CFU} \mathrm{cm}{ }^{-2}$, the first experiment fell very slightly short of this with a final mean $\log _{10}$ (TVC) of 6.94 (Table 1).

As indicated in previous spoilage experiments with poultry [19], the use of $\mathrm{pH}$ as an indicator of spoilage or remaining shelf life in meats would be insufficient. In the case of earlier experiments on poultry, $\mathrm{pH}$ fluctuated prior to spoilage and only rose significantly once bacterial lev-
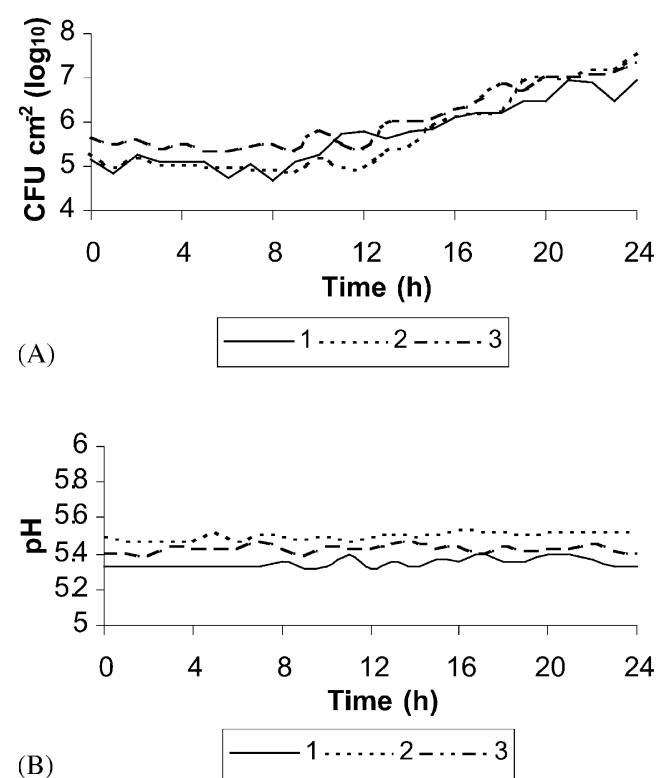

Fig. 2. (A) Bacterial growth curves and (B) $\mathrm{pH}$ levels observed through the series of three experiments [1-3]. Total viable counts of spoilage bacteria were measured in triplicate after $48 \mathrm{~h}$ at $25^{\circ} \mathrm{C}$. els reached $10^{8} \mathrm{CFU} \mathrm{cm}{ }^{-2}$. Fig. 2 illustrates the bacterial growth curves and $\mathrm{pH}$ levels throughout the series of three experiments. In the case of the experiments on rump beef, the initial mean $\mathrm{pH}$ was 5.42 and the final mean $\mathrm{pH}$ 5.43. Moreover, over the three experiments the $\mathrm{pH}$ fluctuated between a narrow range and never fell below 5.32 or above 5.53, demonstrating the strong buffering capacity of beef $[55,56]$.

Whilst the mean level of bacteria for the three experiments was in excess of $10^{7} \mathrm{CFU} \mathrm{cm}{ }^{-2}$, the olfactory characteristics, in comparison to spoiled poultry breast meat at the same level of bacterial spoilage, where very different. Whilst spoiled poultry at $10^{7} \mathrm{CFU} \mathrm{\textrm {cm } ^ { - 2 }}$ began to develop a sweet 'dairy' type aroma due to production of esters by the dominant spoilage bacteria [53], the spoilage of beef at this level was much less offensive in terms of the production of malodours. This difference in sensory characteristics could be a result of several factors, such as the genera of the dominant spoilage microflora, meat type, storage conditions prior to the experiments or the strong buffering capacity demonstrated in the case of the beef experiments [52].

The mean FT-IR spectra collected from pre- and post-spoiled beef from 1850 to $850 \mathrm{~cm}^{-1}$ are shown in Fig. 3, these have been calculated from the mean of the spectra at the start of the three experiments and the mean of the spectra from end of the experiments at $24 \mathrm{~h}$. These spectra are from beef rump steak carrying $\sim 2 \times 10^{5}$ and $\sim 2 \times 10^{7} \mathrm{CFU} \mathrm{cm}^{-2}$, respectively, and are both data-rich and not biased to any groups of chemicals associated with any particular group of metabolites. Whilst the spectra illustrated in Fig. 3 are mean spectra, the entire set consisted of 450 spectra from all three experiments, each consisting of 441 wavenumbers, and these are the data that will be analysed by chemometric methods.

FT-IR spectra are complex and multidimensional in nature, which does not lend them to simple visual interpretation. Therefore, linear regression methods and machine learning approaches were employed to analyse these complex high dimensional spectral patterns $[44,57,58]$ in order to extract pertinent biological information and attempt to correlate known bacterial numbers with the FT-IR spectra collected from the surface of the spoiling beef.

\subsection{Supervised analysis using PLS}

The supervised learning method of PLS regression was calibrated and cross-validated with both the FT-IR spectral 


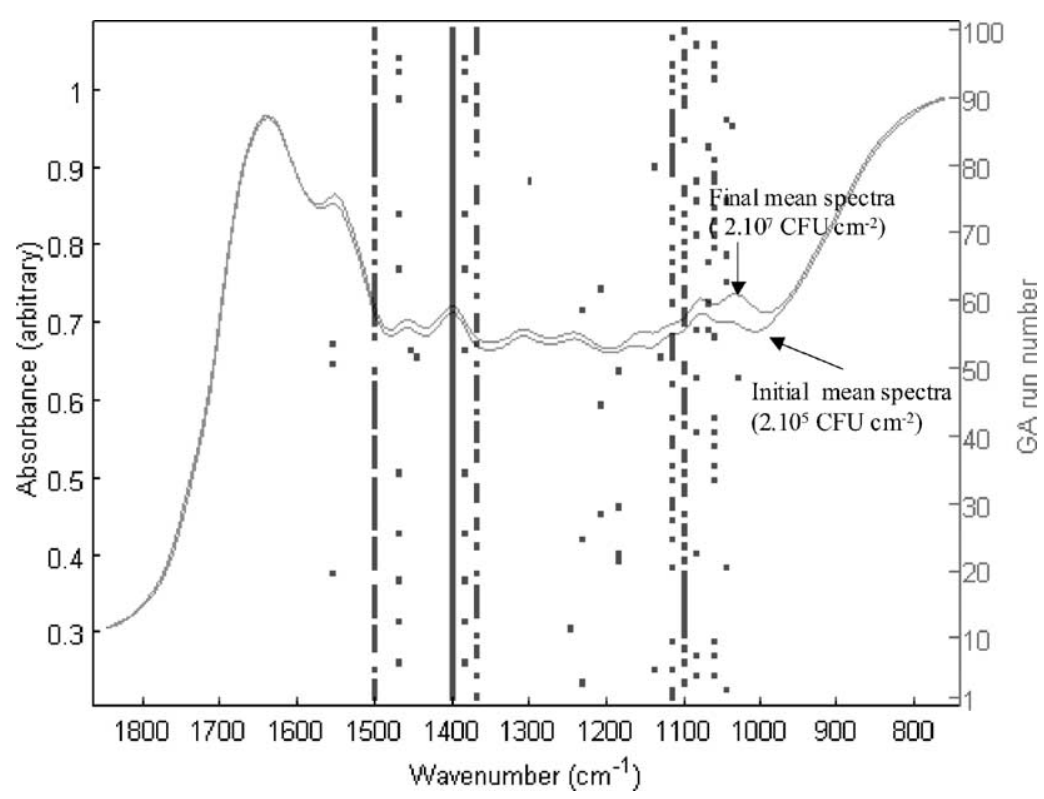

Fig. 3. Mean FT-IR spectra from the initial and final measurements from the three beef spoilage experiments. Also shown is the number of times that a set of four optimum wavenumbers were selected, from each of $100 \mathrm{GA}$ runs that are related to the spoilage process.

data and the known $\log _{10}$ (TVC) values from experiments 1 and 2 , respectively (see Table 2 for details and TVC levels), before being challenged by the independent and previously 'unseen' test set data from experiment 3. The plots of the estimates versus the known $\log _{10}$ (TVC) shown in Fig. 4 illustrate that FT-IR/PLS predictions are within $\sim 0.5 \operatorname{logs}$ of the ideal fit. These predictions are close to the ideal log proportional fit (i.e. $\log (y)=\log (x))$ and so show that this method can be used to assess the spoilage status of the beef.

This demonstrated that PLS gave accurate results at $2 \times 10^{5} \mathrm{CFU} \mathrm{cm}^{-2}$ for microbial spoilage on beef, which is an order lower than those obtained on previous experiments on poultry where the limit of detection was $2 \times 10^{6} \mathrm{CFU} \mathrm{cm}^{-2}$. Whilst this is a significant improvement in the limit of detection using this approach, it must be stated that this is dictated by the bacterial numbers on the meat surface at the point of purchase. It is likely that if it were possible to conduct experiments on meat immediately post-mortem that are not already contaminated with significant bacterial loads that the detection limit could be pushed lower.

From Fig. 3 it was evident that FT-IR spectra collected directly from the surface of beef, contained biochemical information that could be correlated with the spoilage status of the samples. This was the case for the data used to produce the PLS model (experiments 1 and 2) and more significantly for data from an independent and 'unseen' experiment (experiment 3). As with the previous analysis undertaken on poultry [19], the next step would be to elucidate which biochemical species were being measured by FT-IR that were related to the spoilage status of the beef.
Table 2

The $\log _{10}$ (TVC) of bacteria acquired from comminuted beef samples from the three experiments

\begin{tabular}{|c|c|c|c|c|}
\hline \multirow[t]{2}{*}{ Time (h) } & \multicolumn{3}{|c|}{ Experiment } & \multirow[t]{2}{*}{ Arithmetic mean } \\
\hline & 1 & 2 & 3 & \\
\hline 0 & $5.18 \mathrm{c}$ & $5.34 \mathrm{c}$ & $5.68 \mathrm{t}$ & 5.45 \\
\hline 1 & $4.87 \mathrm{v}$ & $5.00 \mathrm{v}$ & $5.52 \mathrm{t}$ & 5.23 \\
\hline 2 & $5.29 \mathrm{c}$ & $5.21 \mathrm{c}$ & $5.62 \mathrm{t}$ & 5.41 \\
\hline 3 & $5.10 \mathrm{v}$ & $5.03 \mathrm{v}$ & $5.42 \mathrm{t}$ & 5.22 \\
\hline 4 & $5.08 \mathrm{c}$ & $5.05 \mathrm{c}$ & $5.52 \mathrm{t}$ & 5.27 \\
\hline 5 & $5.12 \mathrm{c}$ & $5.01 \mathrm{c}$ & $5.37 \mathrm{t}$ & 5.20 \\
\hline 6 & $4.73 v$ & $5.02 \mathrm{v}$ & $5.38 \mathrm{t}$ & 5.12 \\
\hline 7 & $5.05 \mathrm{v}$ & $4.95 \mathrm{v}$ & $5.48 \mathrm{t}$ & 5.22 \\
\hline 8 & $4.67 \mathrm{c}$ & $4.95 \mathrm{c}$ & $5.52 \mathrm{t}$ & 5.19 \\
\hline 9 & $5.08 \mathrm{c}$ & $4.90 \mathrm{c}$ & $5.38 \mathrm{t}$ & 5.17 \\
\hline 10 & $5.27 \mathrm{v}$ & $5.20 \mathrm{v}$ & $5.84 \mathrm{t}$ & 5.54 \\
\hline 11 & $5.75 \mathrm{v}$ & $4.99 \mathrm{v}$ & $5.50 \mathrm{t}$ & 5.52 \\
\hline 12 & $5.81 \mathrm{v}$ & $4.98 v$ & $5.41 \mathrm{t}$ & 5.52 \\
\hline 13 & $5.63 \mathrm{v}$ & $5.39 \mathrm{v}$ & $6.02 \mathrm{t}$ & 5.76 \\
\hline 14 & $5.82 \mathrm{c}$ & $5.46 \mathrm{c}$ & $6.06 \mathrm{t}$ & 5.84 \\
\hline 15 & $5.84 \mathrm{c}$ & $5.97 \mathrm{c}$ & $6.10 \mathrm{t}$ & 5.98 \\
\hline 16 & $6.10 \mathrm{v}$ & $6.17 \mathrm{v}$ & $6.31 \mathrm{t}$ & 6.20 \\
\hline 17 & $6.19 \mathrm{v}$ & $6.23 \mathrm{v}$ & $6.48 \mathrm{t}$ & 6.32 \\
\hline 18 & $6.23 \mathrm{c}$ & $6.28 \mathrm{c}$ & $6.88 \mathrm{t}$ & 6.57 \\
\hline 19 & $6.47 \mathrm{c}$ & $6.95 \mathrm{c}$ & $6.76 \mathrm{t}$ & 6.77 \\
\hline 20 & $6.49 \mathrm{c}$ & $7.06 \mathrm{c}$ & $7.07 \mathrm{t}$ & 6.94 \\
\hline 21 & $6.95 \mathrm{v}$ & $7.00 \mathrm{v}$ & $7.06 \mathrm{t}$ & 7.00 \\
\hline 22 & $6.92 \mathrm{c}$ & $7.20 \mathrm{c}$ & $7.10 \mathrm{t}$ & 7.09 \\
\hline 23 & $6.48 \mathrm{v}$ & $7.21 \mathrm{v}$ & $7.18 \mathrm{t}$ & 7.06 \\
\hline 24 & $6.94 \mathrm{c}$ & $7.58 \mathrm{c}$ & $7.39 t$ & 7.38 \\
\hline
\end{tabular}

All measurements were taken in triplicate after incubation at $25^{\circ} \mathrm{C}$ for $48 \mathrm{~h}$ and these were used, in conjunction with FT-IR spectra, to calibrate (c), cross-validate (v), and test (t) the PLS model. 


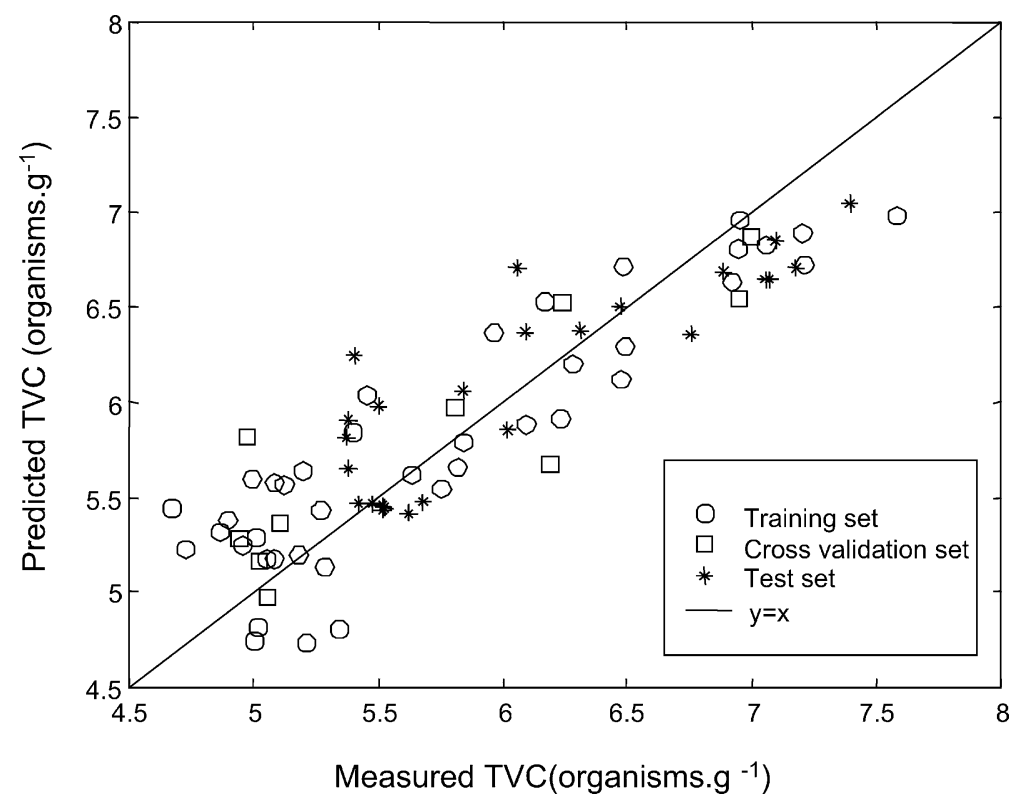

Fig. 4. The estimates from PLS vs. the true $\log _{10}$ (TVC). The data points are the averages of the six measurements. The RMS error in these measurements is $0.43,0.56$ and $0.44 \operatorname{logs}$ for the calibration, cross-validation and independent test sets, respectively.

\subsection{Evolutionary computation}

\subsubsection{Genetic algorithms}

As stated previously, GA-MLR was applied so as to extract subsets of $3,4,5,6,8,10,15$ and 20 wavenumbers that were related to the bacterial numbers over the series of three experiments (Fig. 5). As the starting population for each GA run was random, 100 GA-MLR runs were performed and the following subsets were found to be optimal for selecting just four wavenumbers which were consistently chosen and these were $1513,1413,1382$ and $1112 \mathrm{~cm}^{-1}$. When the GA was used to look for the other predetermined subsets of wavenumbers greater than four it was found that the above four wavenumbers were always chosen and the degree of discrimination did not improve compared with selecting a subset of four, thus a GA that selected four wavenumbers would be considered the most parsimonious. When a GA was used to selected only three input vari-

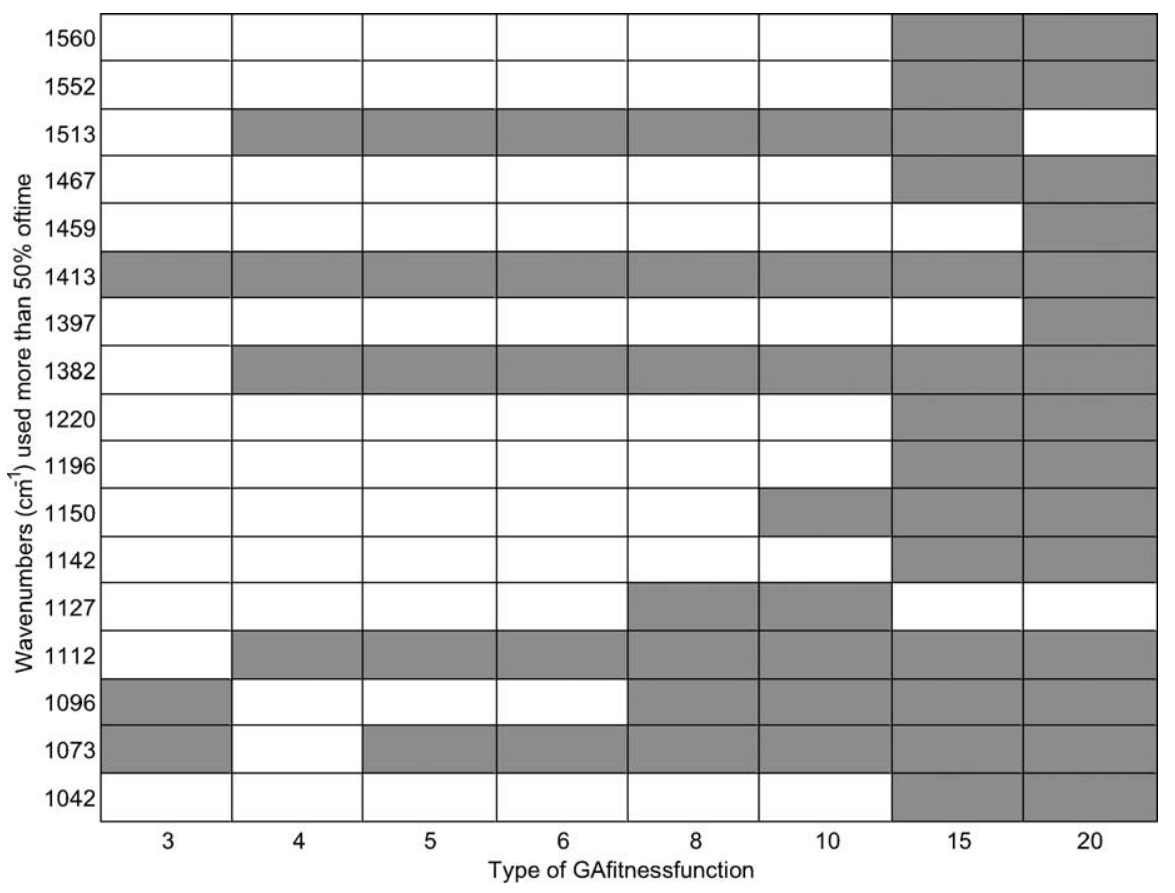

Fig. 5. Combination of all the results from the $8 \mathrm{GA}$ configurations and shows the wavenumbers selected for $>50 \%$ of the time for each of the runs. The wavenumbers selected are shaded. The 'optimum' wavenumber configuration was four. 
ables, only the wavenumber at $1413 \mathrm{~cm}^{-1}$ was consistently chosen.

\subsubsection{Genetic programming}

GP analyses were evolved to determine the wavenumbers associated with the bacterial spoilage of fresh beef over $24 \mathrm{~h}$. By contrast to previous experiments with poultry [19] where the analysis was a threshold of $10^{7}$, these analyses were trained in a quantitative fashion to predict the $\log _{10}$ (TVC). As with the GAs the initial populations were produced randomly and so 20 separate GPs were evolved. For the GP analysis the frequency of the number of times each input (wavenumber) was used for the 20 evolved populations was calculated and plotted against the wavenumber of the infrared light (Fig. 6). This figure shows that the dominant area of the spectra associated with the bacterial spoilage of fresh beef was 1413 and $1405 \mathrm{~cm}^{-1}$. For comparison we have also included the PLS first latent variable loadings in Fig. 6, where it is clear that PLS also selects the area around 1413 and $1405 \mathrm{~cm}^{-1}$ but has additional areas with higher weighting, particularly in the vicinity of the amide I and II bands from 1700 to $1500 \mathrm{~cm}^{-1}$, that are not selected by the GP or indeed GA. The wavenumber selected at $1413 \mathrm{~cm}^{-1}$ was also selected by the GA-MLR method and further to this the wavenumber at $1405 \mathrm{~cm}^{-1}$ is also within the same functional group region $\left(1420-1400 \mathrm{~cm}^{-1}\right)$ ascribable to $\mathrm{C}-\mathrm{N}$ stretching from amides $[59,60]$. Table 3 shows the top 10 wavenumbers and their frequencies selected by GP.

\subsection{Spectral interpretation}

The optimal subset of four wavenumbers selected by GA for correlating the infrared spectra with bacterial spoilage
Table 3

The top 10 wavenumbers evolved by the GP analyses most closely associated with the bacterial spoilage of beef

\begin{tabular}{lcl}
\hline $\begin{array}{l}\text { Wavenumber } \\
\left(\mathrm{cm}^{-1}\right)\end{array}$ & Frequency $^{\mathrm{a}}$ & Vibration \\
\hline 1413 & 200.6 & $\mathrm{C}-\mathrm{N}$ from amides \\
1405 & 182.4 & $\mathrm{C}-\mathrm{N}$ from amides \\
1374 & 80.3 & $\mathrm{C}-\mathrm{N}$ from amines \\
1104 & 73.9 & $\mathrm{C}-\mathrm{N}$ from amines \\
1552 & 59.0 & $\mathrm{CNH}$ from amides or $\mathrm{N}-\mathrm{H}$ from amines \\
872 & 53.9 & $\mathrm{C}-\mathrm{H}$ from aromatic \\
1390 & 47.8 & $\mathrm{NO}$ nitro group \\
1529 & 46.3 & $\mathrm{CNH}$ from amides \\
973,1181 & 45.1 & $\mathrm{P}-\mathrm{O}$ from phosphorus \\
1181 & 44.1 & $\mathrm{C}-\mathrm{N}$ from amines \\
\hline
\end{tabular}

${ }^{a}$ The frequency of a wavenumber being selected was expressed as a percentage of the total tree population for each GP. These 20 GPs were then summed to give this frequency.

of fresh beef were ascribable to an amide II CNH combination vibration (combination of $\mathrm{C}-\mathrm{N}$ stretch and $\mathrm{N}-\mathrm{H}$ bend at $\left.1513 \mathrm{~cm}^{-1}\right)$, a second amide vibration $(\mathrm{C}-\mathrm{N}$ stretch at $\left.1413 \mathrm{~cm}^{-1}\right)$, a nitro group $\left(\mathrm{NO}_{2}\right.$ symmetrical stretch at $\left.1382 \mathrm{~cm}^{-1}\right)$, and finally an amine vibration $(\mathrm{C}-\mathrm{N}$ stretch at $1112 \mathrm{~cm}^{-1}$ ). It was interesting to note that except for one wavenumber selection at $1382 \mathrm{~cm}^{-1}$, the other three wavenumbers were amide or amine bands; it is possible that the nitro group could arise from the proteolytic degradation of proteins, but there is no direct evidence of this.

Apart from this similarity in chemical terms, all the wavenumbers selected were different from those selected to determine the bacterial spoilage in poultry, where the most important wavenumbers were found to be 1096 and $1683 \mathrm{~cm}^{-1}$ [19]. As beef is a different substrate than poultry, in (bio)chemical terms (vide supra) and in particular the ratio

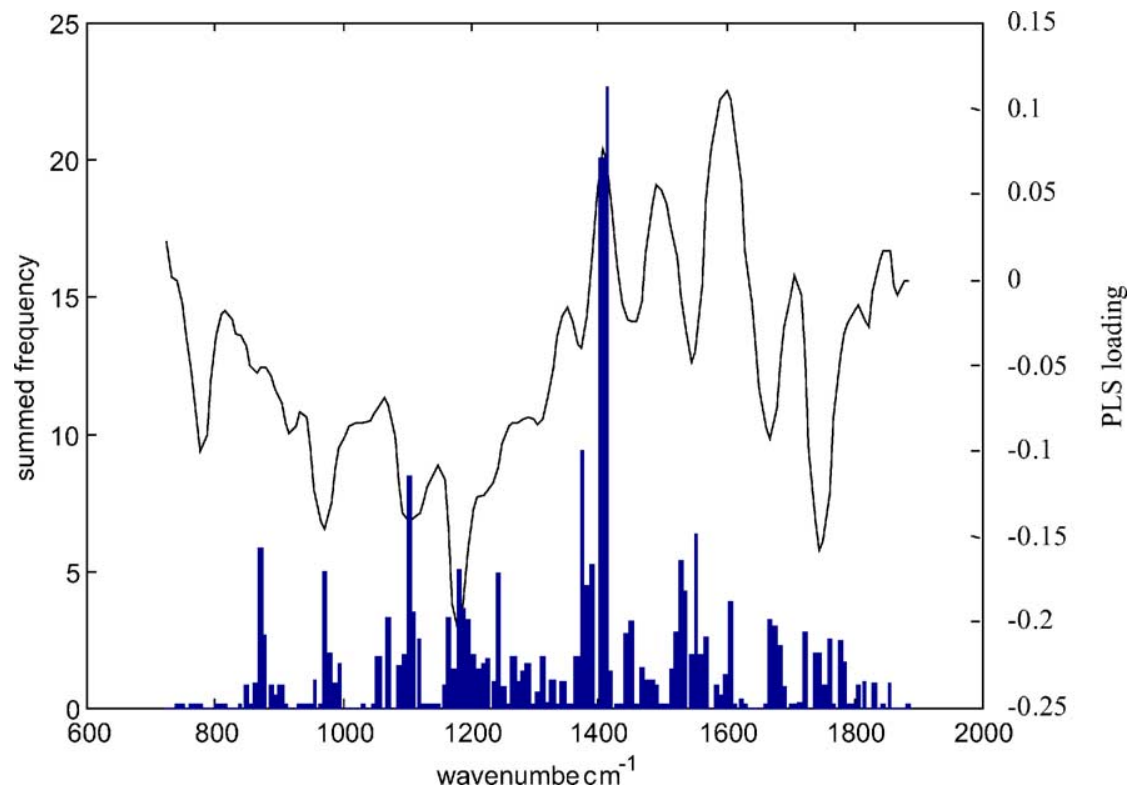

Fig. 6. Summed frequency plot from GP analysis of the number of times each input (wavenumber), normalised to $100 \%$, was used for the 20 evolved populations. The dominant region is between 1413 and $1405 \mathrm{~cm}^{-1}$. Also shown is the PLS first latent variable loading. 
of glycogen to type of muscle, it is therefore likely that these two different meats will be colonised by different microflora. This will lead to different biochemical spoilage processes occurring. In addition, the lower level of glycogen in beef will lead to earlier proteolysis with lower bacterial loads.

In the case of the wavenumbers selected by GP (Table 3), the first two wavenumbers (1413 and $\left.1405 \mathrm{~cm}^{-1}\right)$ are the most dominant and ascribable to $\mathrm{C}-\mathrm{N}$ stretch from amides. The next two most important vibrations (1374 and $1104 \mathrm{~cm}^{-1}$ ) can both be assigned to the $\mathrm{C}-\mathrm{N}$ stretch from free amines. The rest of the selected wavenumbers are shown in Table 3 are predominantly ascribable to amides, amines, whilst nitro, aromatic ring and $\mathrm{P}-\mathrm{O}$ vibrations also feature.

\section{Conclusion}

FT-IR spectroscopy, in combination with linear regression using PLS and evolutionary computational-based machine learning methods was able to correlate infrared spectra with the bacterial spoilage process in beef. However, the model used to achieve this was not as accurate as that used to predict bacterial spoilage in poultry. It is possible that this was due to the spoilage processes in beef being different from those in poultry, however, the bacterial contamination load in beef was significant lower than that observed in chicken and ranged from $5 \times 10^{4}$ to $4 \times 10^{7} \mathrm{CFU} \mathrm{cm}^{-2}$ compared to $2 \times 10^{6}$ to $2 \times 10^{9} \mathrm{CFU} \mathrm{cm}^{-2}$.

Analyses of the FT-IR spectra using genetic algorithms and genetic programming selected wavenumber vibrations from within the region $1420-1400 \mathrm{~cm}^{-1}$, with both evolutionary computational methods selecting the specific vibration at $1413 \mathrm{~cm}^{-1}$ from $\mathrm{C}-\mathrm{N}$ attributable to amides; whilst other vibrations that were selected were from free amines (e.g., 1112 and $1374 \mathrm{~cm}^{-1}$ ). This suggests that the most significant functional groups selected which can be correlated to bacterial spoilage are those from amides and amines. It is likely that this is due to the onset of proteolysis, this hypothesis is in agreement with the literature [61] and as observed by our previous experiments using FT-IR to analyse the metabolic spoilage process on chicken [19].

\section{Acknowledgements}

We are indebted to the Agri-Food and Engineering and Biological Systems Committees of the UK BBSRC for supporting this work and we are very grateful to Graham Price for technical assistance.

\section{References}

[1] S. Cousens, P.G. Smith, H. Ward, D. Everington, R.S.G. Knight, M. Zeidler, G. Stewart, E.A.B. Smith-Bathgate, M.A. Macleod, J. Mackenzie, R.G. Will, Lancet 357 (2001) 1002-1007.
[2] S. Fox, Infect. Med. 18 (2001) 69.

[3] T. Lloyd, S. McCorriston, C.W. Morgan, A.J. Rayner, Agric. Econ. 25 (2001) 347-357.

[4] K. Handa, N. Kreiger, Publ. Health Nutr. 5 (2002) 757-767.

[5] L. Kushi, E. Giovannucci, Am. J. Med. 113 (2002) 63-70.

[6] A. Navarro, M.P. Diaz, S.E. Munoz, M.J. Lantieri, A.R. Eynard, Nutrition 19 (2003) 7-10.

[7] GIRA World Meat Facts Book, International Meat SecretariatGIRA, Geneva, 1997.

[8] D.I. Ellis, R. Goodacre, Trends Food Sci. Technol. 12 (2001) 414 424

[9] J.M. Jay, Modern Food Microbiology, Chapman \& Hall, London, 1996.

[10] A. Davies, R. Board, Blackie, The Microbiology of Meat and Poultry, London, 1998

[11] R. Betts, New Food 2 (1999) 9-16.

[12] T.C. Jackson, G.R. Acuff, J.S. Dickson, in: M.P. Doyle, L.R. Beuchat, T.J. Montville (Eds.), Food Microbiology: Fundamentals and Frontiers, ASM Press, Washington, DC, 1997, pp. 83-100.

[13] G.J.E. Nychas, C.C. Tassou, J. Sci. Food Agric. 74 (1997) 199-208.

[14] G.J.E. Nychas, E.H. Drosinos, R.G. Board, in: A. Davies, R. Board (Eds.), The Microbiology of Meat and Poultry, Blackie, London, 1998, pp. 288-320.

[15] P. Braun, K. Fehlhaber, C. Klug, K. Kopp, Food Microbiol. 16 (1999) 531-540.

[16] K.V. Kumudavally, A. Shobha, T.S. Vasundhara, K. Radhakrishna, Meat Sci. 59 (2001) 411-415.

[17] Y. Suzuki, R. Usami, K. Horikoshi, H. Okuma, Sensors Mater. 13 (2001) 129-136.

[18] D. Mayr, R. Margesin, E. Klingsbichel, E. Hartungen, D. Jenewein, F. Schinner, T.D. Mark, Appl. Environ. Microbiol. 69 (2003) $4697-$ 4705.

[19] D.I. Ellis, D. Broadhurst, D.B. Kell, J.J. Rowland, R. Goodacre, Appl. Environ. Microbiol. 68 (2002) 2822-2828.

[20] D.I. Ellis, G.G. Harrigan, R. Goodacre, in: R. Goodacre, G.G. Harrigan (Eds.), Metabolic Profiling: Its Role in Biomarker Discovery and Gene Function Analysis, Kluwer Academic Publishers, Boston, 2003.

[21] J. Schmitt, H.C. Flemming, Int. Biodeterior. Biodegr. 41 (1998) 1-11.

[22] J.K. Gillie, J. Hochlowski, G.A. Arbuckle-Keil, Anal. Chem. 72 (2000) 71R-79R.

[23] R. Goodacre, E.M. Timmins, P.J. Rooney, J.J. Rowland, D.B. Kell, FEMS Microbiol. Lett. 140 (1996) 233-239.

[24] R. Goodacre, E.M. Timmins, R. Burton, N. Kaderbhai, A.M. Woodward, D.B. Kell, P.J. Rooney, Microbiology (UK) 144 (1998) 11571170 .

[25] D. Naumann, D. Helm, H. Labischinski, Nature 351 (1991) 81-82.

[26] M. Kummerle, S. Scherer, H. Seiler, Appl. Environ. Microbiol. 64 (1998) 2207-2214.

[27] E.M. Timmins, S.A. Howell, B.K. Alsberg, W.C. Noble, R. Goodacre, J. Clin. Microbiol. 36 (1998) 367-374.

[28] G. Kos, H. Lohninger, R. Krska, Vib. Spectrosc. 29 (2002) 115-119.

[29] N.N. Kaderbhai, D. Broadhurst, D.I. Ellis, R. Goodacre, D.B. Kell, Comp. Funct. Genom. 4 (2003) 376-391.

[30] D.B. Dahlberg, S.M. Lee, S.J. Wenger, J.A. Vargo, Appl. Spectrosc. 51 (1997) 1118-1124.

[31] L. Dolmatova, C. Ruckebusch, N. Dupuy, J.P. Huvenne, P. Legrand, Appl. Spectrosc. 52 (1998) 329-338.

[32] O. Al-Jowder, M. Defernez, E.K. Kemsley, R.H. Wilson, J. Agric. Food Chem. 47 (1999) 3210-3218.

[33] M. Mitsumoto, S. Maeda, T. Mitsuhashi, S. Ozawa, J. Food Sci. 56 (1991) 1493-1496.

[34] G. Monin, Meat Sci. 49 (1998) S231-S243.

[35] O. Al-Jowder, E.K. Kemsley, R.H. Wilson, J. Agric. Food Chem. 50 (2002) 1325-1329.

[36] R.R. Gangidi, A. Proctor, F.W. Pohlman, J. Food Sci. 68 (2003) 124-127. 
[37] C.N. Banwell, E.M. McCash, Fundamentals of Molecular Spectroscopy, McGraw-Hill, London, 1994.

[38] H. Martens, T. Næs, Multivariate Calibration, Wiley, Chichester, 1989.

[39] D.L. Massart, B.G.M. Vandeginste, L.M. Budgens, S. Dejong, P.J. Lewi, J. Smeyers-Verbeke, Handbook of Chemometrics and Qualimetrics: Part A, Elsevier, Amsterdam, 1997.

[40] R.O. Duda, P.E. Hart, D.G. Stork, Pattern Classification, 2nd ed., Wiley, New York, 2001.

[41] A. Jones, A.D. Shaw, G.J. Salter, G. Bianchi, D.B. Kell, in: R.J. Hamilton (Ed.), Lipid Analysis of Oils and Fats, Chapman \& Hall, London, 1998, pp. 317-376.

[42] J.H. Holland, Adaption in Natural and Artificial Systems: An Introductory Analysis with Applications to Biology, Control, and Artificial Intelligence, MIT Press, Cambridge, MA, 1992.

[43] T. Bäck, D.B. Fogel, Z. Michalewicz, Handbook of Evolutionary Computation, IOP Publishing/Oxford University Press, Oxford, 1997.

[44] D. Broadhurst, R. Goodacre, A. Jones, J.J. Rowland, D.B. Kell, Anal. Chim. Acta 348 (1997) 71-86.

[45] J.R. Koza, Genetic Programming: On the Programming of Computers by Means of Natural Selection, MIT Press, Cambridge, MA, 1992.

[46] J.R. Koza, Genetic Programming II: Automatic Discovery of Reusable Programs, MIT Press, Cambridge, MA, 1994.

[47] J.R. Koza, F.H. Bennett, M.A. Keane, D. Andre, Genetic Programming III: Darwinian Invention and Problem Solving, Morgan Kaufmann, San Francisco, 1999.

[48] D.B. Kell, R.M. Darby, J. Draper, Plant Physiol. 126 (2001) 943-951.
[49] R. Goodacre, Vib. Spectrosc. 32 (2003) 33-45.

[50] S. Vaidyanathan, D.I. Broadhurst, D.B. Kell, R. Goodacre, Anal. Chem. 75 (2003) 6679-6686.

[51] W. Banzhaf, P. Nordin, R.E. Keller, F.D. Francone, Genetic Programming: An Introduction, Morgan Kaufmann, San Francisco, 1998.

[52] M.P. Doyle, L.R. Beuchat, T.J. Montville, Food Microbiology: Fundamentals and Frontiers, ASM Press, Washington, DC, 1997.

[53] M.R. Adams, M.O. Moss, Food Microbiology, Royal Society of Chemistry, Cambridge, 2000.

[54] F.J.G. Schreurs, Worlds Poult. Sci. J. 56 (2000) 319-346.

[55] M.S. Madruga, D.S. Mottram, J. Sci. Food Agric. 68 (1995) 305-310.

[56] E. Puolanne, R. Kivikari, Meat Sci. 56 (2000) 7-13.

[57] A.D. Shaw, M.K. Winson, A.M. Woodward, A.C. McGovern, H.M. Davey, N. Kaderbhai, D. Broadhurst, R.J. Gilbert, J. Taylor, É.M. Timmins, B.K. Alsberg, J.J. Rowland, R. Goodacre, D.B. Kell, in: T. Scheper (Ed.), Advances in Biochemical Engineering/Biotechnology, vol. 66, Springer-Verlag, Berlin, 1999, pp. 83-114.

[58] R.C. Beavis, S.M. Colby, R. Goodacre, P.B. Harrington, J.P. Reilly, S. Sokolow, C.W. Wilkerson, in: R.A. Meyers (Ed.), Encyclopedia of Analytical Chemistry, Wiley, Chichester, 2000, pp. 11558-11597.

[59] D. Lin-Vien, N.B. Colthup, W.G. Fateley, J.G. Grasselli, The Handbook of Infrared and Raman Characteristic Frequencies of Organic Molecules, Academic Press, Boston, 1991.

[60] I.A. Degen, Tables of Characteristic Group Frequencies for the Interpretation of Infrared and Raman Spectra, Acolyte Publications, Harrow, UK, 1997.

[61] R.H. Dainty, Int. J. Food Microbiol. 33 (1996) 19-33. 